\title{
Drought tolerance and ion accumulation of rice following application of additional potassium fertilizer
}

\begin{abstract}
Five levels of water stress cycle (control flooded, control saturated, 5, 10, and 15 days of irrigation interval) and three potassium fertilization levels $[80 \mathrm{~kg}, 120 \mathrm{~kg}$, and $\mathrm{kg} 160$ dipotassium oxide (K2O) hai 1] were exposed to investigate the influence of potassium fertilizer for minimizing water stress effect and maximizing productivity of rice. Different phyto-physiological parameters as well as uptake of major nutrient elements [nitrogen $(\mathrm{N})$, phosphorus $(\mathrm{P})$, potassium $(\mathrm{K})$, calcium $(\mathrm{Ca})$, magnesium $(\mathrm{Mg})$, iron $(\mathrm{Fe})$ ] were examined. It was observed that rice yield, harvest index, and other physiological parameters reduces with increasing duration of water stress while application of additional potassium fertilizer has progressive impact on those parameters. From our observation, 10 days of watering cycle with potassium fertilization at $120 \mathrm{~kg} \mathrm{~K} 2 \mathrm{O}$ hai 1 produces highest grain yield and harvest index. Uptake of major nutrient elements was also enhanced by potassium fertilizer. Therefore, it can be stated that additional potassium fertilizer application could be useful to mitigate water stress effect in rice.
\end{abstract}

Keyword: Drought stress; Nutrient uptake in rice; Potassium fertilization; Water stress cycle 